\title{
Lactate Release, Concentration in Blood, and Apparent Distribution Volume after Intense Bicycling
}

\author{
Jon Ingulf MEDB $\varnothing$ and Karin TOSKA* \\ National Institute of Occupational Health, N-0033-8149 Oslo, Norway; and \\ * Royal Norwegian Air Force Institute of Aviation Medicine, N-0313-14 Oslo, Norway
}

\begin{abstract}
To study the release of lactate from muscle and its relationship to the blood lactate concentration during and after intense bicycling, young men cycled at $5.5 \mathrm{~W} \mathrm{~kg}^{-1}$ body mass for $2 \mathrm{~min}$ to exhaustion or stopped after $1 \mathrm{~min}$ (nonexhaustive ride). The leg's release of lactate during and after each ride was taken from the measured blood flow and lactate concentrations in arterial and femoral-venous blood. Muscle biopsies were taken in separate experiments and analyzed for lactate. During the bicycling, 6 to $10 \%$ of the lactate produced was released to the blood. During exercise and for the first few minutes after, the rate of lactate release did not differ between 2 min exhaustive and 1 min nonexhaus-
\end{abstract}

tive bicycling. The integrated release (exercise plus recovery) for the 1 min bicycling was 60 to $80 \%$ of the corresponding value of the 2 min exhaustive bicycling. In the late recovery, the blood lactate concentration was 3 to 5 times higher after 2 min exhaustive bicycling than after the 1 min nonexhaustive bicycling. There was thus a mismatch between the amount of lactate released and measured concentration in blood, reflecting a smaller distribution volume after the exhaustive bicycling. The blood lactate concentration may therefore not be a good measure of the lactate production and anaerobic energy release during bicycling. [Japanese Journal of Physiology, 51, 303-312, 2001]

Key words: anaerobic energy release, arterio-venous difference, blood flow, exercise, lactate.

High-intensity exercise depends on energy not only from aerobic processes, but also from anaerobic processes. The main anaerobic source of energy is a breakdown of glycogen to lactate in the working muscles. Part of the lactate produced is released to the blood where it is easily measured. It has been known for more than 70 years that the blood lactate concentration may not reflect the concentration in exercised or stimulated muscle [1]. The blood lactate concentration is nevertheless often used to quantify the anaerobic energy release during exercise.

A quantitative evaluation of the blood lactate concentration and to what extent it reflects the anaerobic energy release is still missing. There is especially incomplete data on how much lactate is released from the muscles and how large the extracellular distribution volume is. We have suggested that at most, $10 \%$ of the lactate produced during intense bicycling is re- leased to the blood during exercise [2], and Hermansen and Vaage [3] suggested that no more than another $10 \%$ is released in the recovery. These views have been criticized, since $35 \%$ of all lactate produced may be released during $3 \mathrm{~min}$ knee extensor exercise, and another $35 \%$ may be released in the recovery period [4]. Thus it could be that former studies $[2,3]$ have underestimated the lactate release during exercise, but it could also be that data from studies activating a small muscle mass (one knee extensor muscle, $\sim 4 \%$ of the body mass [4]) are not relevant for exercise activating a large muscle mass (bicycling, $\sim 25 \%$ of the body mass), and vice versa.

For the same anaerobic energy release during exercise, the peak blood lactate concentration is higher after exhaustive than after nonexhaustive treadmill running [5] and bicycling [6], and the blood lactate concentration differs systematically between subjects

Received on September 1, 2000; accepted on February 6, 2001

Correspondence should be addressed to: Jon Ingulf Medbø: National Institute of Occupational Health, POB 8149 dep. N-0033-8149 Oslo, Norway. Tel: +47-23-19-51-00, Fax: +47-23-19-52-01, E-mail: Jon.Medbo@stami.no 
even when the anaerobic energy releases are the same [5]. This could mean that the amount of lactate released differs between subjects and between experimental conditions. However, even small electrolytes such as bicarbonate [7] and lactate [8] distribute slowly in the extracellular space, taking 10-20 min before near equilibration is reached. It could be that the distribution volumes differ between subjects and experimental conditions, thus giving different blood lactate concentrations even when the amounts released are the same.

To examine the relationship between the leg's release of lactate and the blood lactate concentration, we let subjects bicycle for $2 \mathrm{~min}$ to exhaustion. We also let the subjects cycle at the same power for $1 \mathrm{~min}$ and thus stop before exhaustion. Blood was drawn from indwelling catheters in the femoral artery and vein, the leg blood flow was measured, and the leg's release of lactate was calculated from these measurements. The extracellular distribution volume of lactate was also estimated. We hypothesized that the distribution volume of lactate released from the leg after exercise may vary between conditions.

\section{SUBJECTS, PROCEDURES, AND METHODS}

Subjects. Eight healthy and moderately trained men $24 \pm 2$ year old (mean \pm SD), $1.83 \pm 0.05 \mathrm{~m}$ tall, and with a body mass of $80 \pm 4 \mathrm{~kg}$ served as subjects in this study. Their maximal $\mathrm{O}_{2}$ uptake was $40 \pm 2$ $\mu \mathrm{mol} \mathrm{s}{ }^{-1} \mathrm{~kg}^{-1} \quad\left(54 \pm 3 \mathrm{ml}_{\mathrm{STPD}} \mathrm{kg}^{-1} \mathrm{~min}^{-1}\right)$. The subjects were thoroughly informed about the purpose of the experiments and the practical details before they gave their written consent to participate. The experiments were approved by the Ethics Committee of Health Region 1 in Norway. Seven subjects served in the catheterization experiments, and the eighth subject served only in the Doppler-flow measurements (see below).

Procedures. All exercise was done on an electrically braked Krogh-type bicycle ergometer [9] at a pedaling frequency of $1.5 \mathrm{~Hz}$. The frequency was continuously shown to the subjects on an analog instrument. Thus only negligible deviations between the preset and the actual power was found in all experiments $[10,11]$. The ergometer was equipped with a work meter counting the flywheel's revolutions and thus also including the run-off after each exercise. Flat pedals with no straps were used, and work was therefore done only during the downward push.

During pretests during the last weeks before the experiments, the maximal $\mathrm{O}_{2}$ uptake was measured, and the highest power each subject could keep for 2 min was established.

In the experiments described below, we measured the leg blood flow during and after exercise. Our preferred method was the ultrasound Doppler method, which is noninvasive, precise, and allows for continuous measurements. However, that method requires that the leg is not moved but kept in a fixed position, which is not possible during bicycling. Moreover, there is an upper limit on the blood flow velocity that our instrument could accept. The leg blood flow during exercise and for about the first 1 min after was too high to be measured by the Doppler ultrasound instrument we used. We therefore used the dye dilution technique during exercise and in the early recovery. That method gave values similar to that of the ultrasound Doppler method in the early recovery.

Catheterization and blood flow measurements by dye dilution. Each subject arrived at the laboratory in the morning after an overnight fast. Catheters (artery: $0.74 \mathrm{~mm}$ inner diameter [i.d.], $1.22 \mathrm{~mm}$ outer diameter [o.d.]; vein: $1.19 \mathrm{~mm}$ i.d., $2.00 \mathrm{~mm}$ o.d.; William Cook Europe, Bjærveskov, Denmark) were inserted into the femoral artery and vein $\sim 2 \mathrm{~cm}$ distal to the inguinal ligament, moved $10-15 \mathrm{~cm}$ proximally and fixed with adhesive tape. Thus blood later sampled from the femoral vein was taken at a site distal to where the femoral vein meets the iliac vein, and blood flow measurements in the femoral artery and vein do not include blood given off to the iliac artery or pooled by the iliac vein. Further details on the sampling design are given elsewhere [12]. After the catheters were inserted, the subject warmed up for $15 \mathrm{~min}$ at a power corresponding to $\sim 50 \%$ of his maximal $\mathrm{O}_{2}$ uptake, followed by a $10 \mathrm{~min}$ rest. He then cycled for $1 \mathrm{~min}$ at the power established during the pretests to lead to exhaustion in $2 \mathrm{~min}$. Blood samples were drawn from the femoral artery and vein in parallel in syringes before the exercise, after $30 \mathrm{~s}$ of exercise, at the end of the exercise, and 1, 3, 6, 10, 15, 20, 30 , and 45 min after the ride.

After a $1 \mathrm{~h}$ rest, the subject warmed up again and the procedures were repeated. During this second experiment, however, he cycled for $\sim 2$ min to exhaustion. Blood samples were drawn before the ride, after 90 s of bicycling, and $0,1,3,6,10,15,20,30,45$, and $60 \mathrm{~min}$ after the exhaustive bout.

After 10, 30, 60, and $90 \mathrm{~s}$ of bicycling, immediately after exercise, and 1 and 3 min into the recovery period, the leg blood flow was measured by the dye dilution technique by injecting indocyanin green (Cardiogreen, Becton Dickinson Microbiology Systems, Cockeysville, MD, USA) in the artery. The concentration of the injected dye was then measured in femoral- 
venous blood on a DC-410 cuvette feeding the signal to a CO-10A cardiac output computer (Waters Instruments, Rochester, MN, USA) and further to a PC run under LabVIEW ${ }^{\mathrm{TM}}$ (Graphical Programs for Instrumentation, National Instruments Corporation, Austin, Texas, USA).

Immediately after each sample was taken, the catheters were flushed with $>5 \mathrm{ml}$ of heparinized isotonic saline, and continuous flushing at a rate of 3 $\mathrm{ml} \mathrm{h}^{-1}$ was also done between each sample [12]. After the experiment, the catheters were removed and a manual compression over the insertion site was kept for $30 \mathrm{~min}$. No hematoma was seen for any subject. A bandage applying moderate pressure was put over the insertion site and kept so for at least $1 \mathrm{~d}$, and the subject was denied all physical activity, including stair climbing and heavy lifting for $1.5 \mathrm{~d}$.

Immediately after each sample was drawn, a volume of $0.5 \mathrm{ml}$ of blood was transferred to a separate tube for measurements of the blood lactate concentration. Within 2 to $5 \mathrm{~min}$ after the sample was taken, a volume of $3 \mathrm{ml}$ of blood was centrifuged at $17.8 \mathrm{~km}$ $\mathrm{s}^{-2}(1,800 \times g)$ for $>10 \mathrm{~min}$. Plasma was then pipetted off, frozen, and stored at $-20^{\circ} \mathrm{C}$ for later analyses of the plasma lactate concentration.

Blood flow measurements with the Doppler ultrasound technique. On a separate day, six subjects (five of those taking part in the catheterization experiments and one other) repeated the 1 min nonexhaustive and the 2 min exhaustive bicycling, separated by a $1 \mathrm{~h}$ rest and new warming up. The leg blood flow was measured repeatedly during each of the $1 \mathrm{~h}$ recovery periods by use of an ultrasound Doppler technique (CFM 750 Vingmed Sound, Horten, Norway; see Walløe and Wesche [13] for details). During these measurements, the duplex transducer was handheld in the groin, and the sample volume was placed in the femoral artery just proximal to the inguinal ligament. The insonication beam angle was kept at 50 gon $\left(45^{\circ}\right)$ under continuous visualization.

Muscle biopsy experiments. On a third day, the subjects again repeated the $1 \mathrm{~min}$ nonexhaustive and the 2 min exhaustive bicycling. Before and immediately after these rides, muscle biopsies were taken from the knee extensor muscle as described in more detail elsewhere [6].

Analyses. The maximal $\mathrm{O}_{2}$ uptake was established as described elsewhere [6]. The lactate concentration in whole blood, plasma, and muscle was measured by enzymatic photofluorometry according to Passoneau and Lowry [14]. Since day-to-day variations could affect at least the measured arterio-venous differences, all samples from each subject were mea- sured on the same day. The error (SD) in single measurements was 0.1 to $0.3 \mathrm{mmol} l^{-1}$ [15].

\section{Calculations and statistics.}

Blood flow measurements. The leg blood flow during exercise was calculated from the measured concentration of indocyanin green in the femoral vein by a program written under LabVIEW ${ }^{\mathrm{TM}}$.

For the ultrasound Doppler blood flow velocity measurements carried out after exercise, a built-in average frequency estimator was used to calculate the cross-sectional average velocity and transferred online to a dedicated data collection program. The internal diameter of the femoral artery was measured on the $2 \mathrm{D}$ scanner image at rest before the exercise. The blood flow in the femoral artery was calculated as the product of the velocity and the cross-section area, assuming a circular cross-section of the artery (see Walløe and Wesche [13] for further details).

Blood flows with the ultrasound Doppler technique were not obtained from two subjects who took part in the catheterization experiments. The blood flows for these two subjects in the recovery after exercises were estimated by using the mean value of the rest of the subjects. Cross-validation [16] suggest that this approach gave unbiased estimates with an imprecision (SD) of $16 \%$ for individual values, giving an estimated standard error of $5 \%$ for the calculated releases. This is much less than the individual variations and is thus regarded as being of little importance here.

The leg's accumulated release of lactate was taken by integrating the rates of release at different time points by the trapezoid method [17].

Comparisons between lactate production and lactate release. In our calculations we assume that the working muscle mass in one leg drained by the femoral vein below the sampling site is $10 \%$ of the body mass. It has been shown that the anaerobic energy release during bicycling can be taken from changes in the lactate and phosphocreatine concentration in the knee extensor muscle by assuming that the values in this muscle represents a muscle mass equal to $25 \%$ of the body mass $[11,18,19]$. Subtracting the mass of the gluteus maximus muscles of about $2 \%$ of the body mass for each muscle (Medbø, unpublished data) leaves a working muscle mass in one leg distal to the blood sampling sites of $\sim 10 \%$ of the body mass. We have calculated the distribution volume of lactate released from the working muscles. If lactate is evenly distributed in the whole blood volume amounting to $7 \%$ of the body or in the whole extracellular volume of $\sim 25 \%$ of the body volume, the corresponding volumes covered by the release from one leg distal to the sampling site are then $\sim 3$ and $10 \%$, respec- 
tively.

Distribution volume. A substance's concentration in a fluid is per definition the amount of substance dissolved divided by the fluid volume. If on the other hand the amount dissolved and its concentration are known, the volume can be taken as their ratio. We have calculated the amount of lactate released from one leg from the measured femoral-venous-arterial differences of lactate and the leg blood flow. Thus the distribution volume of the lactate released from the leg was taken as the ratio between the amount released and the measured concentrations in blood and plasma. The released lactate is schematically first distributed in the blood, then in the interstitial fluid, and later possibly taken up in other tissues. Thus if the calculated volume was no more than the blood volume ( $3 \%$, see above), the blood lactate concentration was used. If the amount released exceeded that found in the blood compartment, the measured plasma lactate concentration, assumed to reflect the concentration of the interstitial fluid in well-perfused tissue too, was also used. To account for lactate present before each exercise, the resting lactate concentrations of 0.6 (whole blood) and $1.0 \mathrm{mmol} l^{-1}$ (plasma) were subtracted from the measured concentrations after exercise before being used in the calculations described above.

Statistics. The data are given as mean \pm SEM unless otherwise stated. Tests of statistical significance were carried out by $t$-tests using Bonferroni-correction for repeated comparisons.

\section{RESULTS}

The subjects were able to cycle at a constant power of $5.48 \pm 0.15 \mathrm{~W} \mathrm{~kg}^{-1}$ body mass for $122 \pm 3 \mathrm{~s}$ to exhaustion. The amount of work done during each of the three exhaustive rides carried out on separate days did not differ significantly $(p=0.40)$.

\section{Blood lactate concentration}

During both exercises the blood lactate concentration rose, and the value continued to rise for some minutes into the recovery period (Fig. 1). The arterial blood lactate concentration rose on average by 101 $\mu \mathrm{mol} l^{-1} \mathrm{~s}^{-1}$ during the 2 min exhaustive ride compared with $12 \mu \mathrm{mol} l^{-1} \mathrm{~s}^{-1}$ in the first minute after the exercise. Later the blood lactate concentration rose slower until the peak lactate concentration in arterial blood of $14.2 \pm 0.8 \mathrm{mmol} \mathrm{l}^{-1}$ was found $214 \pm 29 \mathrm{~s}$ after the end of the exercise. The value remained nearly constant in the period 1 to 6 min after exercise (Fig. $1)$.

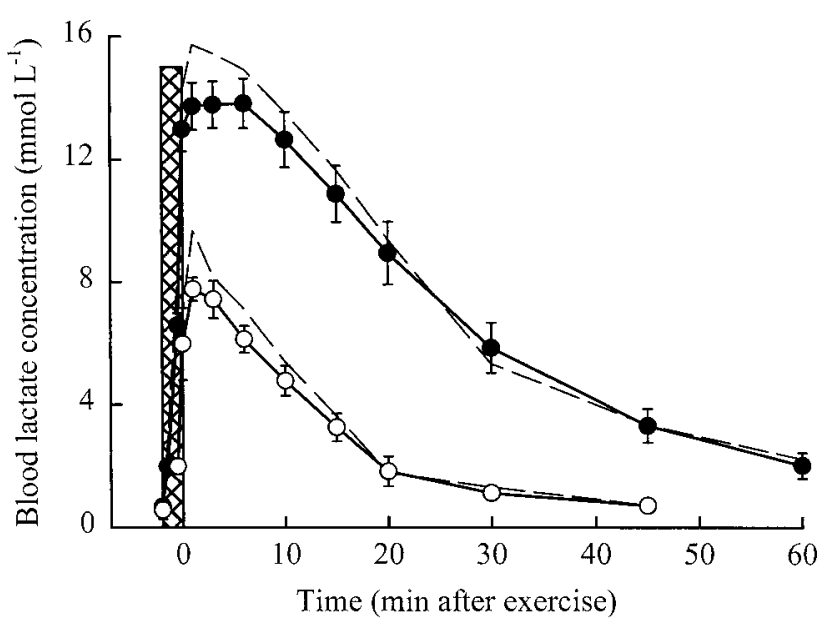

Fig. 1. Arterial blood lactate concentration during and after 2 min exhaustive bicycling (O) and for $1 \mathrm{~min}$ bicycling at the same power (nonexhaustive, $\bigcirc$ ). The thin dashed curves show the lactate concentration in femoralvenous blood. The bar marks the bicycling. The data are mean \pm SEM of seven subjects. Error bars not shown are hidden by the symbols; for the data in venous blood, error bars are not shown for sake of clarity.

During the $1 \mathrm{~min}$ nonexhaustive ride, the lactate concentration of arterial blood rose by a rate of 90 $\mu \mathrm{mol} l^{-1} \mathrm{~s}^{-1}$, which was not different from that during the exhaustive rides. The peak lactate concentration in arterial blood of $8.0 \pm 0.5 \mathrm{mmol} l^{-1}$ was seen $116 \pm 17 \mathrm{~s}$ after the exercise $(p<0.001$ vs. the 2 min ride). The value fell thereafter, and $10 \mathrm{~min}$ into the recovery it had fallen $38 \%$. At that time point and for the rest of the recovery period, the value after the nonexhaustive bout was 15 to $40 \%$ of the corresponding value after the 2 min exhaustive bicycling.

During the first few minutes of the recovery period, the lactate concentration in the femoral vein was 1 to $2 \mathrm{mmol} l^{-1}$ higher than the corresponding value in the artery. Later in the recovery, the difference was less (Fig. 1). In the recovery period, the plasma lactate concentration in arterial blood was $\sim 60 \%$ higher than the corresponding values in whole blood, both for the $1 \mathrm{~min}$ nonexhaustive and for the $2 \mathrm{~min}$ exhaustive rides (see, for example, Medbø et al. [12] for details).

\section{Muscle lactate concentration}

To allow calculation of the total lactate production, the muscle lactate concentration before and immediately after the exercise was measured in a third experiment (Table 1).

\section{Leg blood flow and lactate release}

The leg's release of lactate was taken from measured femoral-venous-arterial differences ( $\mathrm{v}-\mathrm{a}$ difference, the negative of the $\mathrm{a}-\mathrm{v}$ difference) and the leg's 
blood flow during and after 2 min exhaustive bicycling and for $1 \mathrm{~min}$ bicycling at the same power (nonexhaustive). The v-a difference of blood lactate peaked at $\sim 2 \mathrm{mmol} l^{-1}$ near the end of both exercises, and for the first $6 \mathrm{~min}$ of the recovery the $\mathrm{v}-\mathrm{a}$ differences were similar for the two experiments ( $p \geq 0.2$; Fig. 2A). In the interval 10 to $20 \mathrm{~min}$ after exercise the $\mathrm{v}-\mathrm{a}$ difference was less after the $1 \mathrm{~min}$ nonexhaustive than after

Table 1. Muscle lactate concentration before and after exercise.

\begin{tabular}{|c|c|c|}
\hline Exercise condition & $\begin{array}{l}\text { Before } \\
\text { exercise }\end{array}$ & $\begin{array}{c}\text { Immediately after } \\
\text { exercise }\end{array}$ \\
\hline 1 min nonexhaustive bicycling & $0.3 \pm 0.1$ & $15.1 \pm 1.7$ \\
\hline 2 min exhaustive bicycling & $0.4 \pm 0.1$ & $26.2 \pm 1.5$ \\
\hline
\end{tabular}

The data are given in $\mathrm{mmol} \mathrm{kg}^{-1}$ wet muscle mass. The exercise was carried out at $5.5 \pm 0.2 \mathrm{~W} \mathrm{~kg}^{-1}$ body mass, either for $1 \mathrm{~min}$ (nonexhaustive) or for $2 \mathrm{~min}$ to exhaustion. The data are mean \pm SEM of seven subjects. Further details are given in a parallel study [6].
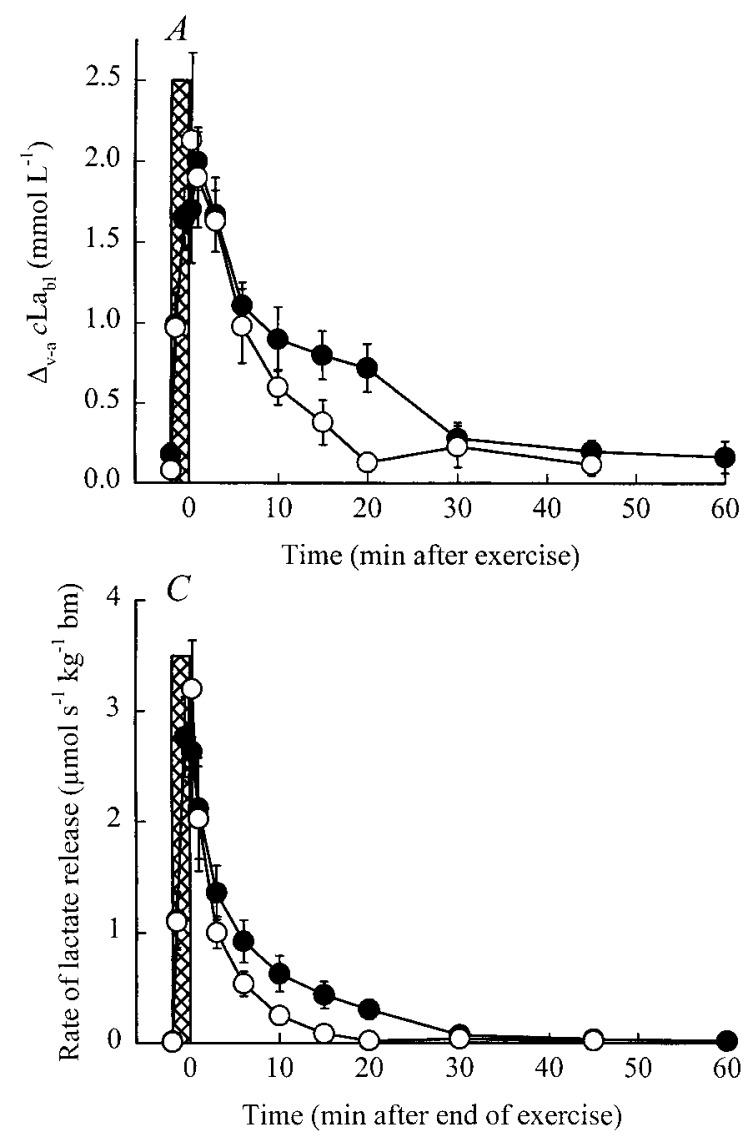

Fig. 2. A: Femoral-venous-arterial difference of the blood lactate concentration $\left(\Delta_{\mathrm{v}-\mathrm{a}} c L a_{\mathrm{bl}}\right)$. B: The leg blood flow. C: The leg's rate of release of lactate taken as the product of the v-a difference and the leg blood flow. D: The leg's integrated release of lactate. The data are during (hatched bar) and after 2 min exhaustive bicycling at the 2 min exhaustive bicycling $(p<0.05)$.

The leg blood flow rose during exercise and peaked at $\sim 2 \mathrm{ml} \mathrm{s}^{-1} \mathrm{~kg}^{-1}$ body mass in the latter part of the exercises and then fell when the bicycling was stopped (Fig. 2B). From 3 min after the exercises and for the rest of the recovery period, the blood flow was less after the $1 \mathrm{~min}$ nonexhaustive bicycling than after 2 min exhaustive bicycling ( $p \leq 0.02)$. The leg's rate of lactate release, taken as the $\mathrm{v}-\mathrm{a}$ difference of the blood lactate concentration times the leg blood flow, rose during the first part of the exercise, peaked at $\sim 3 \mu \mathrm{mol} \mathrm{s}^{-1} \mathrm{~kg}^{-1}$ body mass near the end of the exercise, and fell thereafter (Fig. 2C). In the interval 6 to $20 \mathrm{~min}$ after exercise, the rate of lactate release was higher after the exhaustive than after the nonexhaustive rides $(p<0.05)$; apart from this there were no systematic differences between the two experiments.

The leg blood flow was measured by the dye dilution technique during the exercise and by the ultrasound Doppler technique in the recovery after. To allow for comparison, the blood flow 3 min into the
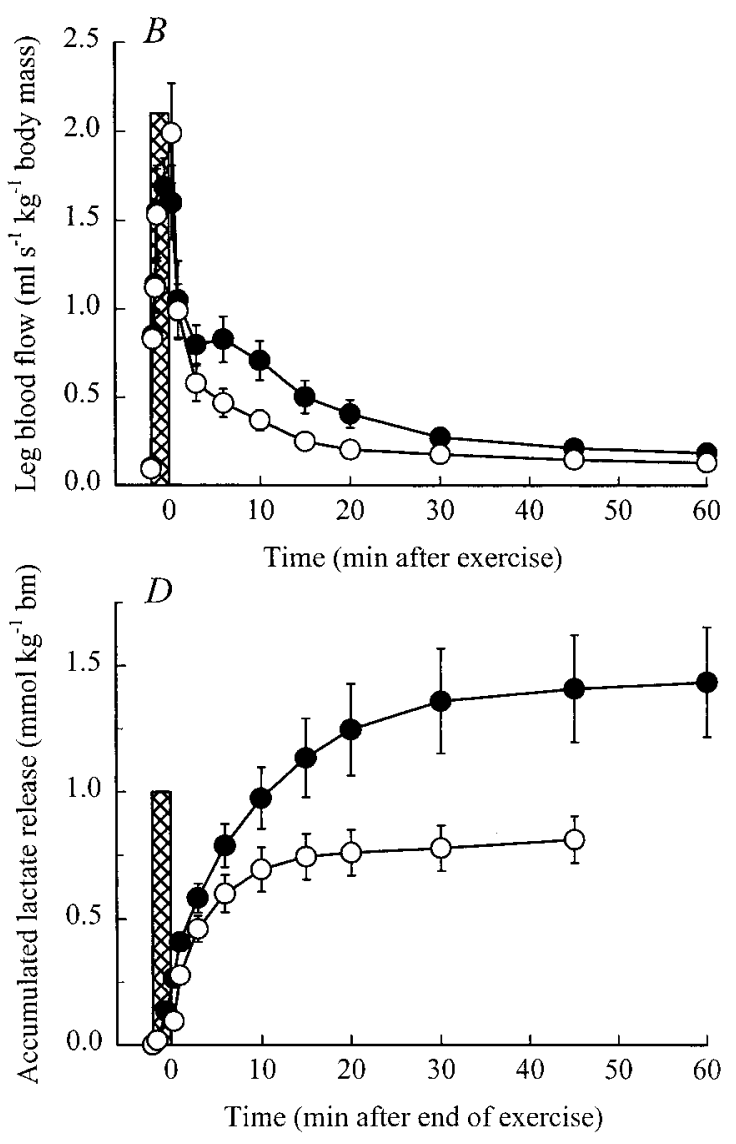

$5.5 \mathrm{~W} \mathrm{~kg}^{-1}(\mathbf{)})$ and for $1 \mathrm{~min}$ bicycling at the same power (nonexhaustive, $\bigcirc$ ). The blood samples were drawn from in dwelling catheters in the femoral artery and vein. The data in $B, C$, and $D$ are expressed per $\mathrm{kg}$ of body mass (bm). The data are mean \pm SEM from seven subjects. Error bars not shown are hidden by the symbols. 
recovery period was measured by both methods, and the two measures agreed within 10 to $15 \%$. A possible systematic error of $15 \%$ is within the random variations between the subjects in this study.

Integrating the leg's release of lactate from the start of each exercise showed that during exercise the leg gave off $94 \pm 9 \mu \mathrm{mol}$ lactate $\mathrm{kg}^{-1}$ body mass $(1 \mathrm{~min}$ nonexhaustive bicycling) and $265 \pm 17 \mu \mathrm{mol}$ lactate $\mathrm{kg}^{-1}$ body mass ( 2 min exhaustive bicycling). These amounts are 12 and $19 \%$ of the total release during the exercise plus recovery period for the $1 \mathrm{~min}$ nonexhaustive and the 2 min exhaustive bicyclings, respectively (see further data below). Data on the muscle lactate concentration on these subjects suggest that the amount released is 6 to $10 \%$ of all produced (see "Calculations and statistics" in the SUBJECTS, PROCEDURES, AND METHOD section for further details). In the $45 \mathrm{~min}$ recovery period, $0.72 \pm 0.09 \mathrm{mmol}$ lactate $\mathrm{kg}^{-1}$ body mass was released to the blood after the 1 min nonexhaustive ride. That corresponds to $7.2 \mathrm{mmol}$ $\mathrm{kg}^{-1}$ wet muscle mass or $\sim 50 \%$ of all produced. After the 2 min ride to exhaustion $1.17 \pm 0.22 \mathrm{mmol} \mathrm{kg}^{-1}$ body mass or $11.7 \mathrm{mmol} \mathrm{kg}^{-1}$ wet muscle mass was released to the blood. That amounts to $45 \%$ of all produced. When compared at the same time points in the recovery period, the amount of lactate released after the $1 \mathrm{~min}$ nonexhaustive bicycling was 60 to $80 \%$ of that released after the $2 \mathrm{~min}$ exhaustive bicycling $(p<0.05)$. Since the blood lactate concentration in relative terms differed much more (Fig. 1), there was an apparent mismatch between the amounts of lactate released from the leg and the blood lactate concentrations caused by these releases.

\section{Estimated distribution volume of the released lactate}

The apparent distribution volume of the lactate released from the leg was taken as the ratio between the amount of lactate released and the increase from rest in the lactate concentrations in whole blood and plasma as further explained in the methods. These distribution volumes rose continuously during the recovery period. Until $3 \mathrm{~min}$ after the exhaustive bicycling, the calculated distribution volume was not larger than the blood volume. Until $10 \mathrm{~min}$ after the nonexhaustive and until $20 \mathrm{~min}$ after the exhaustive bicycling, the calculated distribution volumes were not larger than those corresponding to the interstitial volume. Later in the recovery, the calculated distribution volumes explode, which is compatible with an uptake in other tissues. From 3 min after exercise and for the rest of the recovery period, the calculated distribution volume of the $1 \mathrm{~min}$ nonexhaustive exercise was larger

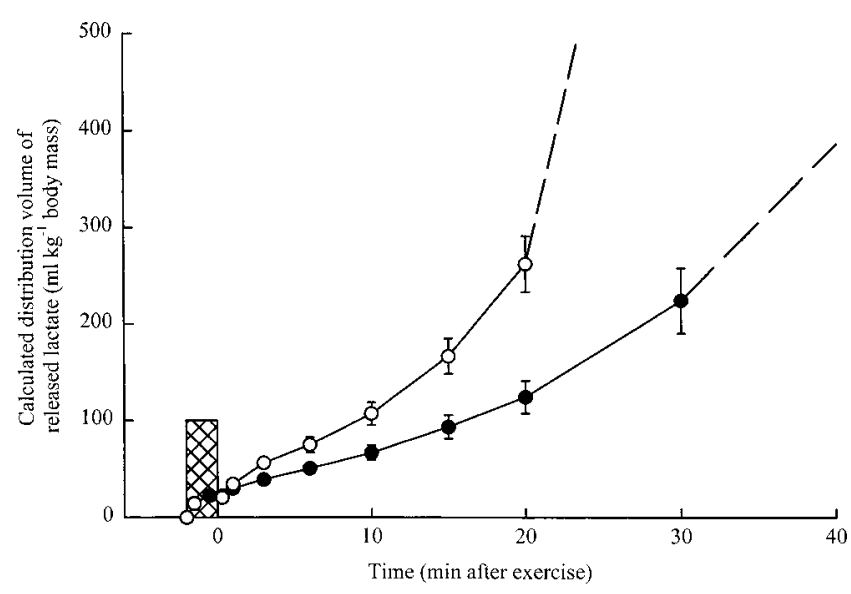

Fig. 3. Calculated distribution volume of the lactate released from one leg below the hip after 2 min exhaustive bicycling (hatched bar) at $5.5 \mathrm{~W} \mathrm{~kg}^{-1}(\Theta)$ and at the same power for $1 \mathrm{~min}$ (nonexhaustive, $\bigcirc$ ). The distribution volumes were calculated by dividing the amount of released lactate by the measured concentration in arterial and femoral-venous whole blood and plasma. The two curves differ significantly from 3 min after exercise and for the rest of the recovery period. The data are mean \pm SEM of seven subjects. Error bars not shown are hidden by the symbols.

than that of the 2 min exhaustive bicycling ( $p<0.01$; Fig. 3).

\section{DISCUSSION}

The main results in this study were first that the blood lactate concentration rose by $12 \mathrm{mmol} l^{-1}$ during the exhaustive exercise at a rate 10 times or more higher than in the recovery period. Second, the measured amount of lactate released from one leg below the hip was only $0.26 \mathrm{mmol} \mathrm{kg}^{-1}$ body mass during the exhaustive exercise. There was a maintained release for $\sim 20 \mathrm{~min}$ into the recovery period, that is, long after the blood lactate concentration had begun to fall. Consequently, the calculated distribution volume of the released lactate rose continuously during the recovery. Then at a given time point the distribution volume was larger after the $1 \mathrm{~min}$ nonexhaustive than after the 2 min exhaustive bicycling.

Lactate release. The $\mathrm{v}-\mathrm{a}$ difference of the blood lactate concentration of 1.5 to $2 \mathrm{mmol}^{-1}$ and the peak leg blood flow of $\sim 2 \mathrm{ml} \mathrm{s}^{-1} \mathrm{~kg}^{-1}$ body mass are similar to values found by others during intense bicycling [20,21]. Thus our measured values used for further calculations are in fair agreement with data obtained by others.

There have been different views on how much of the lactate that is produced is further released to the blood during intense exercise when large muscles are 
engaged. We first suggested that $\sim 15 \%$ of all produced was released during 2 min treadmill running or exhaustive bicycling $[10,18]$. As a result of measurements of the muscle glycogen concentration and other metabolites during exercise, we later suggested that no more than $10 \%$ of all lactate was released to the blood during exercise [2,11]. That view has been heavily criticized [22], since the amount released during a 3 min one-leg knee extensor exercise may be as much as $35 \%$ of all produced [4].

The muscle lactate concentration in the knee extensor muscle rose by $26 \mathrm{mmol} \mathrm{kg}^{-1}$ wet muscle mass during the $2 \mathrm{~min}$ exhaustive ride, corresponding to a lactate production of $2.6 \mathrm{mmol} \mathrm{kg}^{-1}$ body mass for the working muscles in one leg below the sampling site. The release during exercise was $0.26 \mathrm{mmol} \mathrm{kg}{ }^{-1}$. Thus this study confirms our former idea $[2,11]$ that no more than $10 \%$ of all lactate produced during bicycling was released to the blood during the ride. This is in relative terms far less than the $35 \%$ found for knee extensor exercise, and the reason for the different conclusions should be sought. Our v-a difference of lactate was less than $2 \mathrm{mmol} l^{-1}$. The leg blood flow was less than $20 \mathrm{ml} \mathrm{s}^{-1} \mathrm{~kg}^{-1}$ working muscle mass, and within $3 \mathrm{~min}$ after exercise it fell to $\sim 8 \mathrm{ml} \mathrm{s}^{-1} \mathrm{~kg}^{-1}$ working muscle mass. The $\mathrm{v}-\mathrm{a}$ difference during Bangsbo et al.'s [4] knee extensor exercise was 3.5 to $4 \mathrm{mmol} l^{-1}$ during most of the 3 to 4 min exercise period; their peak blood flow was $\sim 24 \mathrm{ml} \mathrm{s}^{-1} \mathrm{~kg}^{-1}$ working muscle mass, and it stayed quite high for several minutes into the recovery. Consequently the lactate release per kilogram of working muscle in that study was 3 to 4 times higher than in our study. Moreover, if $35 \%$ of the lactate produced during intense bicycling or treadmill running activating a muscle mass of $\sim 25 \%$ of the body mass was released during exercise, the blood lactate concentration would rise to 55 to $60 \mathrm{mmol} l^{-1}$ if the distribution volume was the same as after knee extensor exercise. Values that high have not been reported. These considerations suggest that the data of Bangsbo et al. [4] may have little relevance for bicycling, treadmill running, or other exercises activating a large muscle mass, and vice versa.

Half of all the lactate recorded released during the 2 min exhaustive exercise was released during the last $30 \mathrm{~s}$ and the first $20 \mathrm{~s}$ of the recovery (the time when the first postexercise blood sample was obtained). Thus for exercise lasting less than $2 \mathrm{~min}$, relatively less lactate may be released to the blood during exercise. If the rates of release are similar to that of the 2 min ride to exhaustion, only 2,3 , and $4 \%$, respectively, of the lactate produced during 10 to 15,30 , and $60 \mathrm{~s}$ exhaustive bicycling $[11,18,23]$ is released to the blood during the exercise in question. We have in former studies not included the lactate release when we have quantified the energy turnover during exercise $[11,23]$, but the calculations above suggest that the error introduced is small.

Our calculations of the amounts of lactate released from the leg disregard a possible redistribution of lactate within the leg, that is, a possible uptake in nonactive tissue within the leg. This is probably a small problem. First, the uptake is only 2 to $3 \mu \mathrm{mol} \mathrm{s}^{-1} \mathrm{~kg}^{-1}$ wet muscle mass even after one-leg exercise that activates a small muscle mass, and the uptake increases by the perfusion $[24,25]$. This latter finding means that a possible uptake would probably be even less in our experiments where the perfusion of nonactive tissues may be reduced. The uptake of lactate in the liver is $\sim 1 \mathrm{mmol} \mathrm{min}^{-1}[26,27]$, which is even less than the uptake in an inactive leg. The uptake in the arm is small during bicycling and too small to be detected in the recovery after exercise [28]. Second, biomechanical analyses show that the hamstring muscles do much work on the ergometer during bicycling, although their contribution is less than that of the knee and hip extensors, and even the calf muscles do 10 to $15 \%$ of the work during bicycling [29, 30]. Therefore, although the lactate concentration in the hamstrings and calf muscles may be less than in the knee extensors at exhaustion, the values are probably much higher than at rest. If that is so, these muscles would release lactate to the blood instead of taking it up. So in contrast to knee extensor exercise, there should not be much inactive muscle tissue in the leg available for a possible uptake. Third, comparing the calf blood flow data of Hermansen and Vaage [3] with ours suggests that $\sim 10 \%$ of the leg blood flow goes to the calf, a value that compares favorably with the calf muscles' part of the work during bicycling. As a result and contrary to the situation for knee extensor exercise [4], there should be no need to occlude the lower leg when blood samples are drawn (Medbø, unpublished observations).

Extracellular distribution volume. We found that the apparent distribution volume of the lactate released from the leg was very small during the exercises, but it rose continuously during recovery. This is in line with other data showing that it takes 10 to $20 \mathrm{~min}$ before even small electrolytes are equilibrated in the extracellular fluid $[7,8]$. What is new in our study is that at each time point, the apparent distribution volume was about twice as large after the $1 \mathrm{~min}$ nonexhaustive as after the 2 min exhaustive ride. We also give quantitative data on the apparent distribution volume at various times. 


\section{J. I. MEDB $\varnothing$ and K. TOSKA}

The lactate concentration in arterial blood rose by a nearly constant rate of $\sim 100 \mu \mathrm{mol} \mathrm{s}^{-1} l^{-1}$ blood during bicycling. In the first minute after, the rate of rise was $\sim 10 \%$ of that during the exercise, and during the next $2 \mathrm{~min}$, it was even less. Despite the slow rate of rise in the lactate concentration in the early recovery and the further fall after the peak value was seen, the leg gave off lactate for $\sim 20 \mathrm{~min}$. This apparent mismatch can be explained by a steadily increasing distribution volume of the released lactate.

It is a common experience that if more than one intense bout of exercise is carried out a few minutes apart, the blood lactate concentration rises less during and after the second and possible third bout than after the first (see, for example, Bodganis et al. [31]). The blood lactate concentration depends not only on the lactate production and release from working muscles. As shown by the following numeric example, the measured concentration is also highly sensitive to variations in the distribution volume of the released lactate: Assume that three intense exercise bouts are carried out a few minutes apart, and after each bout $100 \mathrm{mmol}$ of lactate is released to the blood. The lactate released after the first bout is distributed in a volume of $10 l$, and the measured concentration therefore rises by $10 \mathrm{mmol}^{-1}$. Assume then that the distribution volumes expand by time, and after the second and third bouts they are 15 and $20 l$, respectively. The measured lactate concentration after the second and third bouts will therefore be $200 \mathrm{mmol} / 15 l=13.3$ $\mathrm{mmol} l^{-1}$ and $300 \mathrm{mmol} / 20 l=15 \mathrm{mmol} l^{-1}$ above the preexercise value, respectively. Thus even though the amounts released were the same after all exercises, the blood lactate concentrations would rise by $10,3.3$, and $1.7 \mathrm{mmol} l^{-1}$, respectively, that is, by a ratio of $6: 2: 1$ between the three bouts in this example. This shows that conclusions on the anaerobic energy release drawn only from changes in the blood lactate concentrations may be very misleading.

It has been quite common to assume that the released lactate is quickly equilibrated throughout not only the extracellular space, but even taken up by nonactive tissues. For example, based on this assumption and measurements of the blood lactate concentration, Freund and co-workers have in several studies modeled the transfer and elimination of lactate within the body after exercise $[32,33]$. Although their modeled data fit closely to their measured values, our study gives reason to question the physical interpretation of their modeling. Moreover, our study showed clear differences between the blood lactate concentrations in the femoral vein and artery, and the values in the finger capillaries differ from the two other entities (not shown here; see, for example, figure 1A in Medbø et al. [6] for a comparison). Thus the fitted model parameters, assumed to reflect basic physiological processes, will probably vary depending on where the blood lactate concentration is measured.

Possible mechanisms for the different distribution volumes. It is well known that during exercise, blood is redistributed to the exercising muscles, and control through the sympathetic nervous system is important. When large muscles are intensively activated, the heart cannot pump enough blood to supply all the muscles with all the $\mathrm{O}_{2}$ they can consume; there is thus an increasing spillover of noradrenalin, reflecting an increasing sympathetic activity, as an increasing muscle mass is engaged [34]. In line with this, a common experience is that it may be difficult to obtain blood from a finger after exercise, especially if the exercise has been carried out to exhaustion. Thus, not only is blood redistributed to the active muscles during exercise. The situation may persist in the recovery after exercise too, and perhaps to a larger extent and for a longer time after exhaustive exercise than after nonexhaustive exercise. If so, the extracellular distribution volume may be less after exhaustive than after nonexhaustive exercise. The very high blood lactate concentrations seen after short exhaustive sprints $[5,6,35]$ may be a consequence of a high sympathetic activity persisting after exhaustive exercise, thus leading to a small distribution volume of the released lactate.

Even if the perfusion of nonactive tissue is reduced after exercise, it may seem surprising that it takes 10 to $20 \mathrm{~min}$ before the apparent distribution volume equaled the extracellular space ([7, 8], this study). By diffusion alone small ions like lactate may distribute over a distance of $0.5 \mathrm{~mm}$ in $\sim 1 \mathrm{~min}$ (time constant of exponential equilibration). Thus if open capillaries are $1 \mathrm{~mm}$ or less apart, full equilibration within the perfused tissue should take place within a few minutes. This view may be too simple, however, since the blood may be unevenly distributed not only in resting, but also in electrically stimulated muscles, and the uneven distribution is seen even over a time span of $10 \mathrm{~min}$ [36]. So even though some parts of inactive tissue may be quite well perfused, other parts may remain poorly perfused for a long time after exercise. If this is true, the apparent distribution volume of released lactate will be small.

Conclusions. Relatively little lactate was released to the blood during exercise, but the release continued after the peak blood lactate concentration was seen. The apparent distribution volume of the released lactate was less after 2 min of exhaustive bicy- 
cling than after 1 min of nonexhaustive bicycling.

We are grateful to Astrid Bolling, Ada Ingvaldsen, Bjørg Ingrid Selberg, and Jorid Thrane Stuenæs for their technical assistance, and to Sigrid Hanem and Harald Noddeland for medical assistance during the experiments. The blood flow data calculated from the measured dye concentration in the femoral-venous blood were collected and analyzed by a dedicated program written by Øystein Klingenberg Hansen. The ultrasound Doppler recordings of the blood velocity in the femoral artery were analyzed by a dedicated data collection and analysis program written by Morten Eriksen. We thank Professor Lars Walløe at the Institute of Physiology, University of Oslo, Norway, for letting us use his laboratory and equipment for these measurements.

\section{REFERENCES}

1. Sacks $J$ and Sacks WC: Blood and muscle lactic acid in the steady state. Am J Physiol 118: 697-702, 1937

2. Medbø Jl: Glycogen breakdown and lactate accumulation during high intensity cycling. Acta Physiol Scand 149: 85-89, 1993

3. Hermansen $L$ and Vaage $O$ : Lactate disappearance and glycogen resynthesis in human muscle after maximal exercise. Am J Physiol Endocrinol Metab 233: E422-E429, 1977

4. Bangsbo J, Gollnick PD, Graham TE, Juel C, Kiens B, Mizuno M, and Saltin B: Anaerobic energy production and $\mathrm{O}_{2}$ deficit-debt relationship during exhaustive exercise in humans. J Physiol (Lond) 422: 539-559, 1990

5. Medbø JI, Mohn A-C, and Tabata I: Blood lactate concentration versus anaerobic energy release during exhausting and nonexhausting treadmill running. Acta Kinesiol Univ Tartuensis 3: 22-37, 1998

6. Medbø JI, Gramvik P, and Tabata I: Blood and muscle lactate concentrations after intense bicycling. submitted

7. Mellemgaard K and Astrup P: The quantitative determination of surplus amounts of acid or base in the human body. Scand J Clin Lab Invest 12: 187-199, 1960

8. Klausen K, Rasmussen B, Clausen JP, and TrapJensen $\mathrm{J}$ : Blood lactate from exercising extremities before and after arm or leg training. Am J Physiol 227: 67-72, 1974

9. Krogh A: A bicycle ergometer and respiration apparatus for the experimental study of muscular work. Skand Arch Physiol 30: 375-394, 1913

10. Medbø JI and Tabata I: Aerobic and anaerobic energy release and work during shortlasting, exhausting bicycle exercise. J Appl Physiol 67: 1881-1886, 1989

11. Medbø JI and Tabata I: Anaerobic energy release in working muscle during $30 \mathrm{~s}$ to 3 min exhausting bicycling. J Appl Physiol 75: 1654-1660, 1993

12. Medbø JI, Hanem S, Noddeland H, and Jebens E: Arterio-venous differences of blood acid-base status and plasma sodium caused by intense bicycling. Acta Physiol Scand 168: 311-326, 2000

13. Walløe $L$ and Wesche J: Time course and magnitude of blood flow changes in the human quadriceps muscles during and following rhythmic exercise. J Physiol (Lond) 405: 257-273, 1988
14. Passoneau JV and Lowry OH: Enzymatic Analysis, Humana Press, Totowa, NJ, pp 188-193, 1993

15. Medbø Jl, Mamen A, Olsen $\mathrm{OH}$, and Evertsen F: Examination of four different instruments for measuring the blood lactate concentration. Scand J Clin Lab Invest 60: 367-380, 2000

16. Efron B and Gong G: A leisurely look at the bootstrap, the jackknife and cross-validation. Am Statist 37: 36-48, 1983

17. Kincaid D and Cheney W: Numerical Analysis. Mathematics of Scientific Computing, Brooks/Cole Publ. Co., Pacific Grove, CA, pp 514-528, 1996

18. Medbø JI, Mohn A-C,Tabata I, Bahr R, Vaage O, and Sejersted OM: Anaerobic capacity determined by maximal accumulated oxygen deficit. J Appl Physiol 64: 50-60, 1988

19. Sahlin K, Ren JM, and Broberg S: Oxygen deficit at the onset of submaximal exercise is not due to a delayed oxygen transport. Acta Physiol Scand 134: 175-180, 1988

20. Lindinger MI, Heigenhauser GJF, McKelvie RS, and Jones NL: Blood ion regulation during repeated maximal exercise and recovery in humans. Am J Physiol Regul Integr Comp Physiol 262: R126-R136, 1992

21. Poole DC, Gaesser GA, Hogan MC, Knight DR, and Wagner P: Pulmonary and leg $\mathrm{VO}_{2}$ during submaximal exercise: implications for muscle efficiency. J Appl Physiol 72: 805-810, 1992

22. Bangsbo J: Letter to the editor. Estimation of lactate release from contracting muscles in man. Acta Physiol Scand 150: 349-350, 1994

23. Medbø JI, Gramvik P, and Jebens E: Aerobic and anaerobic energy release during $10 \mathrm{~s}$ and $30 \mathrm{~s}$ bicycle sprints. Acta Kinesiol Univ Tartuensis 4: 122-146, 1999

24. Ahlborg G, Hagenfeldt L, and Wahren J: Substrate utilization by the inactive leg during one-leg or arm exercise. J Appl Physiol 39: 718-723, 1975

25. Bangsbo J, Aagaard T, Olsen M, Kiens B, Turcotte LP, and Richter EA: Lactate and $\mathrm{H}^{+}$uptake in inactive muscles during intense exercise in man. J Physiol (Lond) 462: 115-133, 1995

26. Rowell LB, Kraning II KK, Evans TO, Kennedy JW, Blackmon JR, and Kusumi F: Splancnic removal of lactate and pyruvate during prolonged exercise in man. $J$ Appl Physiol 21: 1773-1783, 1966

27. Åstrand P-O, Hultman E, Juhlin-Dannfelt $A$, and Reynolds G: Disposal of lactate during and after strenuous exercise in man. J Appl Physiol 61: 338-343, 1986

28. Poortmans JR, Bossche JD-V, and Leclercq R: Lactate uptake by inactive forearm during progressive leg exercise. J Appl Physiol 45: 835-839, 1978

29. Ericson MO, Bratt $\AA$, Nisell R, Arborelius UP, and Ekholm J: Power output and work in different muscle groups during ergometer cycling. Eur J Appl Physiol 55: 229-235, 1986

30. Ericson MO: Mechanical muscle power output and work during ergometer cycling at different work loads and speeds. Eur J Appl Physiol 57: 382-387, 1988

31. Bodganis GC, Nevill ME, and Lakomy HKA: Effect of previous dynamic exercise on power output during repeated maximal sprint cycling. J Sports Sci 12: 363370, 1994 


\section{J. I. MEDB $\varnothing$ and K. TOSKA}

32. Freund $\mathrm{H}$ and Zouloumian $\mathrm{P}$ : Lactate after exercise in man: I. Evolution kinetics in arterial blood. Eur J Appl Physiol 46: 121-133, 1981

33. Freund $H$, Oyono-Enguelle $S$, Heitz A, Marbach J, Ott $\mathrm{C}$, and Gartner M: Effect of exercise duration on lactate kinetics after short muscular exercise. Eur J Appl Physiol 58: 534-542, 1986

34. Savard G, Richter EA, Strange S, Kiens B, Christensen NJ, and Saltin B: Norepinephrin spillover from skeletal muscle during exercise in humans: role of muscle mass. Am J Physiol Heart Circ Physiol 257: H1812$\mathrm{H} 1818,1989$

35. Osnes JB, Hermansen L: Acid-base balance after maximal exercise of short duration. J Appl Physiol 32: 59-63, 1972

36. Iversen PO, Standa M, and Nicolaysen G: Marked regional heterogeneity in blood flow within a single skeletal muscle at rest and during exercise hyperaemia. Acta Physiol Scand 136: 17-28, 1989 